\title{
Pattern of Cardiovascular Drugs Use in Outpatient Department in a Tertiary Care Hospital of Bangladesh
}

\author{
Udoy Shankar Roy ${ }^{1}$, AK M Monwarul Islam² ${ }^{2}$ Mohsin Ahmed ${ }^{3}$, Murshidur Rahman Khan $^{4}$, Nihar Ranjan Sarker ${ }^{5}$
}

\begin{abstract}
Objective: The objective of the present study was to provide recent population-based information on use of cardiovascular drugs in outpatients in a tertiary care hospital of Dhaka, Bangladesh.

Methods: A prospective study of cardiovascular prescriptions of Outpatient Department of Department of Cardiology of Shaheed Suhrawardy Medical college hospital Dhaka, Bangladesh was carried out.

A total of $\mathbf{2 1 5}$ prescriptions were collected for the study in Shaheed Suhrawardy Medical College Hospital Dhaka, Bangladesh from July 2015 to June 2016. The prescriptions were evaluated for rationality based on WHO model list of essential medicines. The prescriptions were critically analyzed using predetermined parameters.
\end{abstract}

Results: Out of 215 prescriptions collected, 120 drugs were found to be repeatedly prescribed. The results revealed that all single dose formulations prescribed were rationally in accordance with WHO essential drug list whereas fixed dose combinations prescribed remain questionable. A pattern of polypharmacy was clearly evident.

Conclusion: Medications are a critical modality for prolongation and improved quality of life. Campaign and intervention should be focused on patients with more than three diagnostic cardiovascular conditions in order to minimize polypharmacy in patients particularly elderly.

Keywords: Cardiac, Medicine, Prescriptions, Bangladesh.

\section{Introduction}

Rational drug prescription is defined as use of least number of drugs to obtain the best possible effect in shortest duration and at a reasonable cost. Rationality of drug prescriptions has been studied in various developing countries ${ }^{1}$. Rational Use of Drugs as defined by the World Health Organization

1. Associate Professor, Department of Cardiology, Shaheed Suhrawardy Medical College, Dhaka, Bangladesh.

2. Associate Professor, Department of Cardiology, National Institute of Cardiovascular Diseases, Dhaka, Bangladesh.

3. Associate Professor, Department of Cardiology, Dhaka medical College, Dhaka, Bangladesh.

4. Assistant Professor, Department of Cardiology Shaheed Suhrawardy Medical College, Dhaka, Bangladesh.

5. Associate Professor, Department of Paediatrics, Shaheed Suhrawardy Medical College, Dhaka, Bangladesh.

Address of Correspondence: Udoy Shankar Roy, Associate Professor, Department of Cardiology, Shaheed Suhrawardy Medical College Hospital, Dhaka, Bangladesh. Email: drudays@gmail.com Contact no: +8801819128105
$(\mathrm{WHO})^{2}$ depends on making correct diagnosis and prescribing appropriate drugs in adequate doses. Globally more than $50 \%$ of drugs are prescribed, dispensed or sold inappropriately ${ }^{3}$. Conveyance of message from prescriber to a patient is referred to as prescription writing. The various unintended outcomes that may

occur as a result of poor prescribing approach include ineffective treatment and exacerbated illness along with distress and harm to the patient with higher cost ${ }^{4}$.

The quality of health care may depend on many activities which may include the correct diagnosis, rational use of drugs in correct doses and dispensing them with proper direction ${ }^{5}$. During internship, medical

graduates prescribe drugs and provide patient care under the guidance of their teachers. This is the period when they

DOI: http://dx.doi.org/10.3329/bhj.v32i2.36090

Copyright $\odot 2017$ Bangladesh Cardiac Society. Published by Bangladesh Cardiac Society. This is an Open Access articles published under the Creative Commons Attribution-NonCommercial 4.0 International License (CC BY-NC). This license permits use, distribution and reproduction in any medium, provided the original work is properly cited and is not used for commercial purposes. 
should form the habit of correct methods of prescribing appropriate drugs in correct doses. They should be encouraged to prescribe essential drugs ${ }^{6}$. Inappropriate prescription culminates in the increase in the cost of medical treatment and in morbidity and mortality. Irrational prescription of drugs also leads to an increase in incident of adverse drug events and to emergence of drug resistance ${ }^{7}$. Monitoring of prescriptions and drug utilization studies can identify the problems and provide feedback to prescribers so as to create awareness about irrational use of drugs. The present study aimed to assess the prescribing patterns of cardiovascular drugs in cardiology outpatient department of Shaheed Suhrawardy Medical College Hospital, Dhaka, Bangladesh

\section{Methods:}

A prospective study was conducted with the consent of Head of the Department of Cardiology in Shaheed Suhrawardy Medical College Hospital, a 750 bedded tertiary care teaching hospital, Dhaka, Bangladesh.

The prescriptions were collected for a period of twelve months from July 2015 to June 2016 from the outpatients suffering from cardio vascular health problem from the hospital outpatient department (OPD) on daily basis including repeated (refilled) prescriptions. A total of 215 prescriptions were collected for the study undertaken.

Each prescription was critically studied for the patient's demographic information (such as patient name, age, gender, address, date of consultation) and drug name, dose strength, dosage form, frequency, duration and quantity. The drugs prescribed in each prescription were carefully noted and following parameters were used to assess the rationality of the prescriptions.

- Segregation of prescription in age wise

- Categorization of drugs prescribed with respective to gender

- Total number of drug prescribed

- Average number of drugs per prescription

- Drug prescribed by brand names versus generic names

- Dosage form

- Duration of therapy

- Therapeutic category

- Number of single dose formulation prescribed

- Number of fixed dose formulation prescribed

Data was analyzed using statistical package for social sciences (SPSS) software version 17. Descriptive statistics was used to analyze the data obtained from the study.

\section{Results:}

Observation of the prescriptions revealed that among the total collected prescriptions of cardiovascular disorders, 120 drugs were repeatedly prescribed. Each patient was prescribed with more than three medicines. Polypharmacy was clearly evidenced in most of the prescriptions.

Parameters evaluated for prescribing pattern

\section{Age in years}

From the analyzed prescriptions only one prescription was prescribed between the age group of 31 to 39 years. Sixty prescriptions were found to be in the age between 40 to 49 years. Eighty prescriptions were in the age group of 50 to 59 years. The numbers of prescriptions falling into the category of age group between 60 to 69 years were sixty followed by fifteen prescriptions in the category of 70 to 79 years.

\section{Gender}

Out of two hundred and fifteen prescriptions reviewed, 150 prescriptions were for male category and the remaining 65 for female.

Drug prescribed by brand versus generic names

Out of 215 prescriptions collected, 120 were repeatedly prescribed among which 90 were of brand names and the remaining were of generic names.

\section{Dosage form}

All the cardiovascular drugs prescribed were in oral dosage forms.

\section{Duration of therapy}

Among the 215 prescriptions collected 30 were prescribed up to 3 months, 80 prescriptions for 6 months and remaining 105 prescriptions for 1 year.

\section{Therapeutic category}

Table 1 and 2 represents the prescribing pattern of cardiovascular drugs in single dose and fixed dose combinations respectively. Most of the drugs prescribed were of single dose formulation along with a few fixed dose combinations. Table 3 and 4 portrays the therapeutic category of cardiovascular drugs in single dose and fixed dose formulation respectively. It is clear that most of the single dose formulations prescribed were of antihypertensives, antianginal and antilipidaemic (Fig 1). From Fig 2 it is clear that anti-platelets and antilipidaemic were the most commonly prescribed in fixed dose combinations. 


\section{Determination of rationality}

The rationality of cardiovascular drugs has been determined by referring WHO model list of essential medicines (March $2010,16^{\text {th }}$ list updated $)^{2}$. The results revealed that most of the prescribed single dose drugs are in accordance with the essential model list but the fixed dose combinations prescribed are not included in the list but used commonly.

Table-I

Prescribing pattern of cardiovascular drugs (Single dose formulation)

\begin{tabular}{lcc}
\hline Cardiovascular Drug & $\begin{array}{c}\text { Number of } \\
\text { prescriptions }\end{array}$ & $\begin{array}{c}\text { Prescribed } \\
\text { pattern (\%) }\end{array}$ \\
\hline Amlodipine & 50 & 23.25 \\
Atenolol & 20 & 9.3 \\
Atorvastatin & 107 & 49.76 \\
Carvedilol & 16 & 7.44 \\
Digoxin & 08 & 3.72 \\
Olmesartan & 39 & 18.14 \\
Asprin & 28 & 13.02 \\
Glyceryl trinitrate & 60 & 27.91 \\
Mononitrate & 42 & 19.53 \\
Metoprolol & 33 & 15.35 \\
Trimetazidine & 04 & 1.86 \\
Ramipril & 32 & 14.88 \\
Losartan potassium & 26 & 12.09 \\
Verapamil & 15 & 6.97 \\
\hline
\end{tabular}

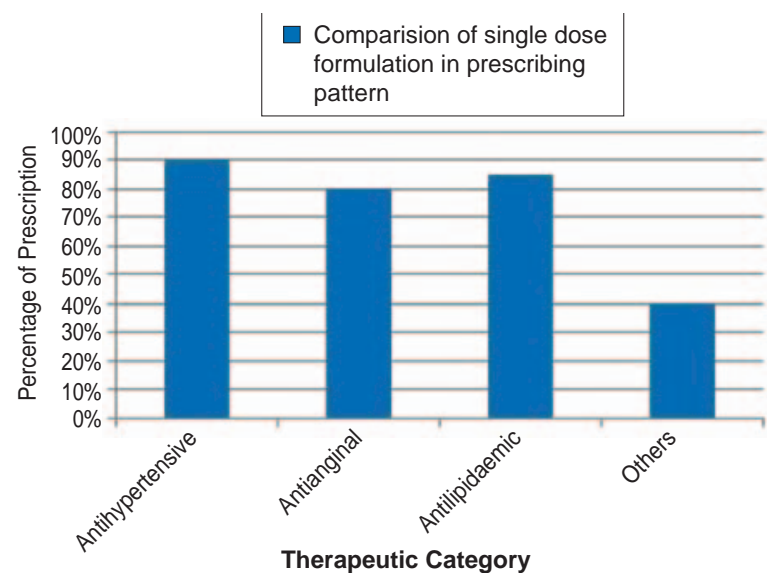

Fig.-1: Comparison of single dose formulations in prescribing pattern.

Table-II

Prescribing pattern of cardiovascular drugs (Fixed dose combinations)

\begin{tabular}{lcc}
\hline Cardiovascular Drug & $\begin{array}{c}\text { Number of } \\
\text { prescriptions }\end{array}$ & $\begin{array}{c}\text { Prescribed } \\
\text { pattern (\%) }\end{array}$ \\
\hline Amlodipine + Atenolol & 06 & 2.79 \\
Amlodipine + Olmesartan & 06 & 2.79 \\
Aspirin + Clopidogrel & 12 & 5.58 \\
Atorvastatin + Aspirin & 12 & 5.58 \\
Furosemide + Spironolactone & 04 & 1.86 \\
Torasemide + Spironolactone & 04 & 1.86 \\
\hline
\end{tabular}

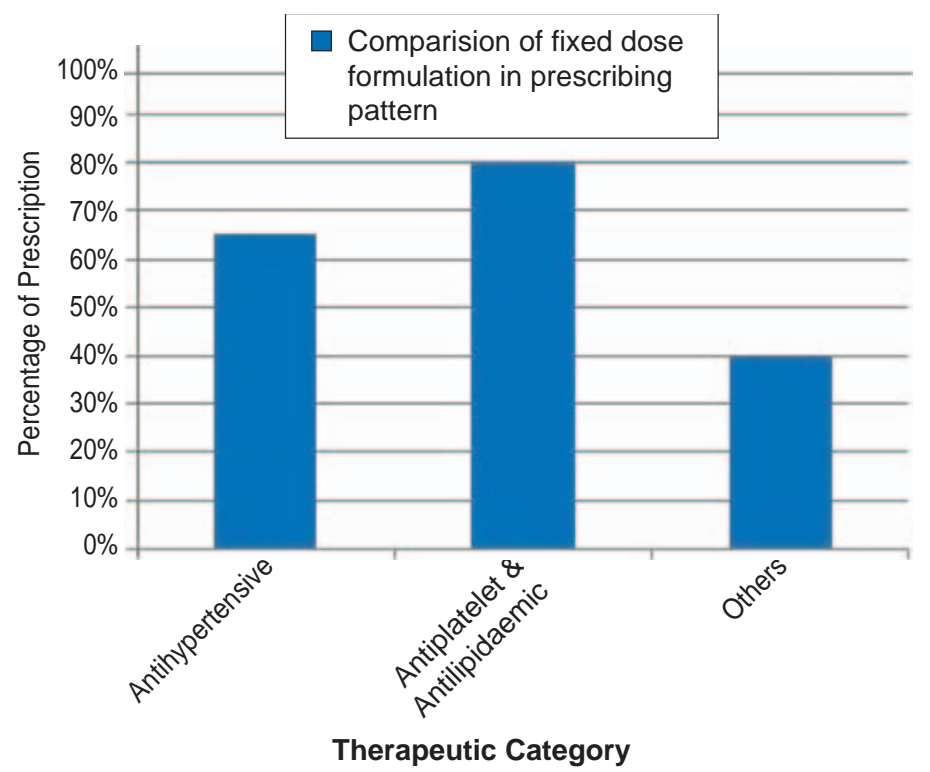

Fig 2: Comparison of fixed dose formulations in prescribing pattern. 
Table-III

Therapeutic category of cardiovascular drugs (Single dose formulation).

\begin{tabular}{lcc}
\hline & Pharmacological Classification & Therapeutic Category \\
\hline Amlodipine & Calcium channel blocker & Antihypertensive \\
Atenolol & Beta blocker & Antihypertensive \\
Atorvastatin & *HMG CoA reductase inhibitor & Anti lipidemic \\
Carvedilol & Beta blocker & Antihypertensive \\
Digoxin & Cardiac glycoside & Congestive Heart Failure \\
Olmesartan & ARB & Antihypertensive \\
Glyceryl trinitrate & Vasodilator & Antianginal and antiarrhythmic \\
Asprin & Cyclooxygenase inhibitor & Antiplatelet \\
Isosorbide mononitrate & Vasodilator & Antianginal and antiarrhythmic \\
Metoprolol & Beta blocker & Antihypertensive \\
Trimetazidine & Vasodilator & Antianginal and antiarrhythmic \\
Ramipril & qACE inhibitor & Antihypertensive \\
Losartan potassium & Angiotensin ll antagonist & Antihypertensive \\
Verapamil & Calcium channel blocker & Antihypertensive \\
\hline
\end{tabular}

*HMG CoA - Hydroxy -3-methyl glutaryl Co-enzyme A; aACE - Angiotensin converting enzyme

Table-IV

Therapeutic category of cardiovascular drugs (Fixed Dose Combinations).

\begin{tabular}{lcc}
\hline Cardiovascular Drug & Pharmacological Classification & Therapeutic Category \\
\hline Amlodipine + Atenolol & Calcium blocker + beta blocker & Antihypertensive \\
Amlodipine + Olmesartan & Calcium blocker + ACE inhibitor & Antihypertensive \\
Aspirin + Clopidogrel & Platelet aggregation inhibitor & Antiplatelet \\
Atorvastatin + Aspirin & HMG CoA reductase inhibitor + & Antilipidaemic and antiplatelet \\
& platelet aggregation inhibitor & Antihypertensive \\
Furosemide+Spironolactone & Loop + Potassium sparing Diuretics & Antihypertensive \\
Torasemide+Spironolactone & Loop + Potassium sparing Diuretics &
\end{tabular}

Table-V

Category of patients according to diagnosis

\begin{tabular}{lcccccccc}
\hline Patients (No.) & IHD & HTN & Post MI Angina & Heart Failure & IHD \& HTN & IHD \& HF & RHD & CHD Arrhythmia \\
\hline Male (150) & 54 & 25 & 10 & 11 & 16 & 9 & 12 & 7 \\
Female (65) & 19 & 14 & 6 & 5 & 4 & 2 & 8 & 3 \\
\hline
\end{tabular}

\section{Discussion}

A prescription by a physician denotes his/her attitude towards the disease and medication ${ }^{8}$. The various prescribing parameters and the distribution of categories of drugs in the prescriptions analyzed in this study provided an insight into the prescribing pattern in Shaheed Suhrawardy medical college hospital, Dhaka,Bangladesh.

Duplication of drug product and cost effectiveness of drugs can be minimized by prescribing drugs in generic names rather than brand names ${ }^{9}$. In this study, most of drugs prescribed were in brand names and it was similar to other type of studies conducted ${ }^{10}$. Higher number of patients in this study was male (Table-5) which correlates with other researchers ${ }^{11}$.

It was observed in present study that most of (83.33\%) the drugs prescribed were of single dose formulations and $16.66 \%$ were of fixed dose combinations. Amlodipine, Glyceryl Trinitrate, Metoprolol, Atorvastatin are the most commonly prescribed drugs found in single dose formulation. Clopidogrel and Aspirin combination was the commonly prescribed fixed dose combination. The high prescribing 
frequency of antihypertensives and antiplatelets in single dose formulations and antiplatelet with antilipidaemic in fixed dose combinations reflects the high prevalence of hypertension and cerebrovascular diseases among the study population.

The therapeutic management of cardiovascular problems has to be straight forward ${ }^{14}$. The present study had certain limitations like short period of study and the study did not consider the prescribing pattern at seasonal variations in disease. The plan mooted in this particular study is to perform over a longer period of time with greater number of prescriptions along with improving the scope of prescription pattern among the cardiovascular drugs in Shaheed Suhrawardy Medical College Hospital, Dhaka,Bangladesh.

This study is to provide clinical pharmacy services by preparing treatment guidelines for various cardiovascular diseases and there by assisting physician for better patient care by minimizing polypharmacy, adverse drug reactions and events, drug interactions etc.

\section{Conclusion}

Medications are a critical modality for prolongation and improved quality of life. The percentage of drugs prescribed with fixed dose combinations was low. The percentage of drugs prescribed by generic name was low and polypharmacy was observed which may be considered by physicians for evaluation. Irrational prescribing can be better avoided by strictly following to the treatment guidelines and ideal prescription writing. In order to improve the prescription behavior and skill, awareness about rational use of drugs may be created by conducting many workshops ${ }^{15}$ and training programme in clinical medicine ${ }^{1 .}$

\section{References:}

1. Rajanandh MG, Ramsamy C, Khan Al. Pattern of cardiovascular drug use in outpatients in a tertiary care hospital. Asian journal of Pharmacology and clinical research 2012; 5:109-112.

2. Vijayakumar TM, Poovi G, Swaroop VSS. Prescribing patterns of fixed dose combination focus on cardiovascular drugs in outpatient department of private hospitals. J Pharmacol Toxicology 2010; 5:215221.

3. WHO, Model list of essential medicines $16^{\text {th }}$ list. Available from: http://www.who.int/ medicines/ publications/ essentialmedici nes/en/.

4. Mohanty BK, Aswini M, Hasamnis AA. Prescription pattern in the department of medicine of a tertiary care hospital in South India. J Clin Diagnostic Res 2010;4: 2047-2051.

5. Alam K, Mishra P, Prabhu M. A study on rational drug prescribing and dispensing in outpatients in a tertiary care teaching hospital of Western Nepal. Kathmandu University Med J 2006;4: 436-443.

6. Al-Junid SM, Sharifa Ezat WP, Surianti S. Prescribing patterns and drug cost among cardiovascular patients in Hospital Universiti Kebangsaan Malaysia. Med J Malaysia 2007;62: 5965

7. Louise S, Eskil J, Cecilia SL. Drug prescribing in public primary care centers Results from prescription studies 1988-1997 in Halland, Sweden. Scand J Prim Health Care 2002;20:236-241.

8. Ranjeeta K, Idris MZ, Vidya B, Anish K, Monika A, Shivendra KS. Assessment of prescription pattern at the public health facilities of Lucknow district. Indian J Pharmacol 2008;40: 243-247.

9. Ghosh R, Neogi JN, Srivastava BS, Sen P. Prescribing trends in a teaching hospital in Nepal. J Nepal Med Assoc 2003;42:346349.

10. Nazima NY, Desi S, Ganguly B. Prescribing pattern in a pediatric outpatient department in Gujarat. Bangladesh J Pharmacol 2009; 4:39-42.

11. Anand H, Jinta J, Gurumurthy P, Grad DC, Madhan R, Shoba G. Prescribing patterns and predictors of highlevel high level polypharmacy in the elderly population; A prospective surveillance study from two teaching hospitals in India. The Amer J Geriatric Pharmacotherapy 2010; 8: 271-280

12. Sharif SI, Shaqra M, Hajjar H. Shamout L, Wess. Patterns of drug prescribing in a hospital in dubai, United Arab Emirates.Libyan J.Med 2007;3.

13. Chobanian AV, Bakris GL, Black HR, Cushamn WC, Green LA, Izzo JL. The seventh report of joint national committee, on prevention, detection, evaluation and treatment of high blood pressure: The JNC 7 report, J Am Med Assoc 2003; 289:25602575.

14. Salman MT, Akram MF, Rahman S, Khan FA, Haseen MA, Khan SW. Drug prescribing pattern in surgical wards of a teaching hospital in North India. Ind J Prac Doc 2008;5: 1-3.

15. Thomas M, Cherian AM, Mathai D. Measuring the impact of focused workshops on rational drug use. Trop Doct 1997;27:206-210. 